\title{
Feasibility of combined spinal - epidural analgesia for implication within enhanced recovery pathways in total hip arthroplasty (THA)
}

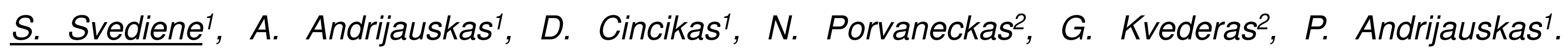
${ }^{1}$ Vilnius University- Faculty of Medicine- Institute of Clinical medicine, Clinic of Anaesthesiology and Intensive Care, Vilnius, Lithuania. 2Vilnius University- Faculty of Medicine- Institute of Clinical medicine, Clinic of Rheumatology, Orthopaedics Traumatology and Reconstructive Surgery, Vilnius, Lithuania.

\section{Background and Aims:}

Objective was to assess feasibility of combined spinal epidural anaesthesia (CSEA) as part of ERAS protocol in THA patients.

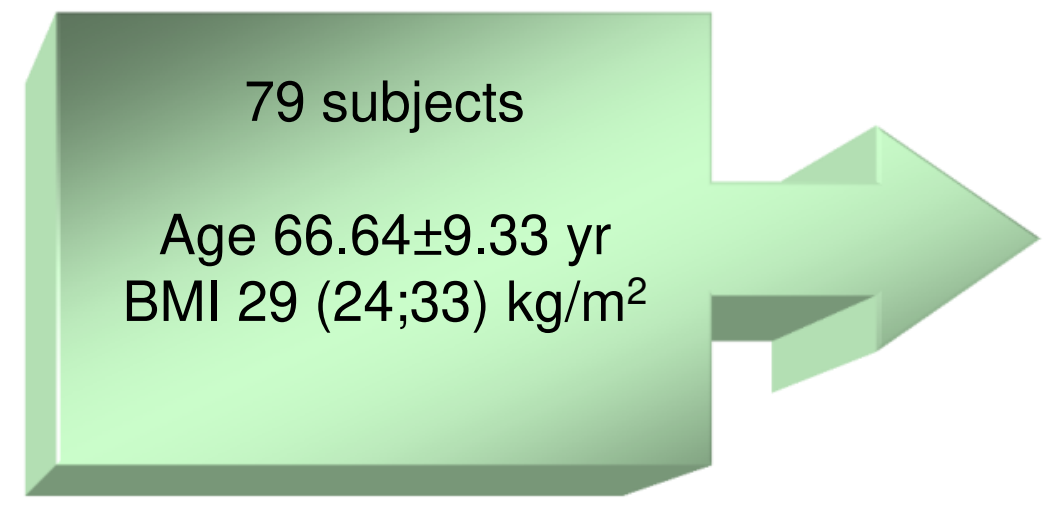

\section{Methods:}

1. Adult ASA II patients were included.

2. Spinal anaesthesia was performed in L2-3 level with $2.5-3 \mathrm{ml}$ of $0.5 \%$ bupivacaine.

3. Postoperative patient controlled epidural analgesia (PCEA) continued until 8 AM next morning.

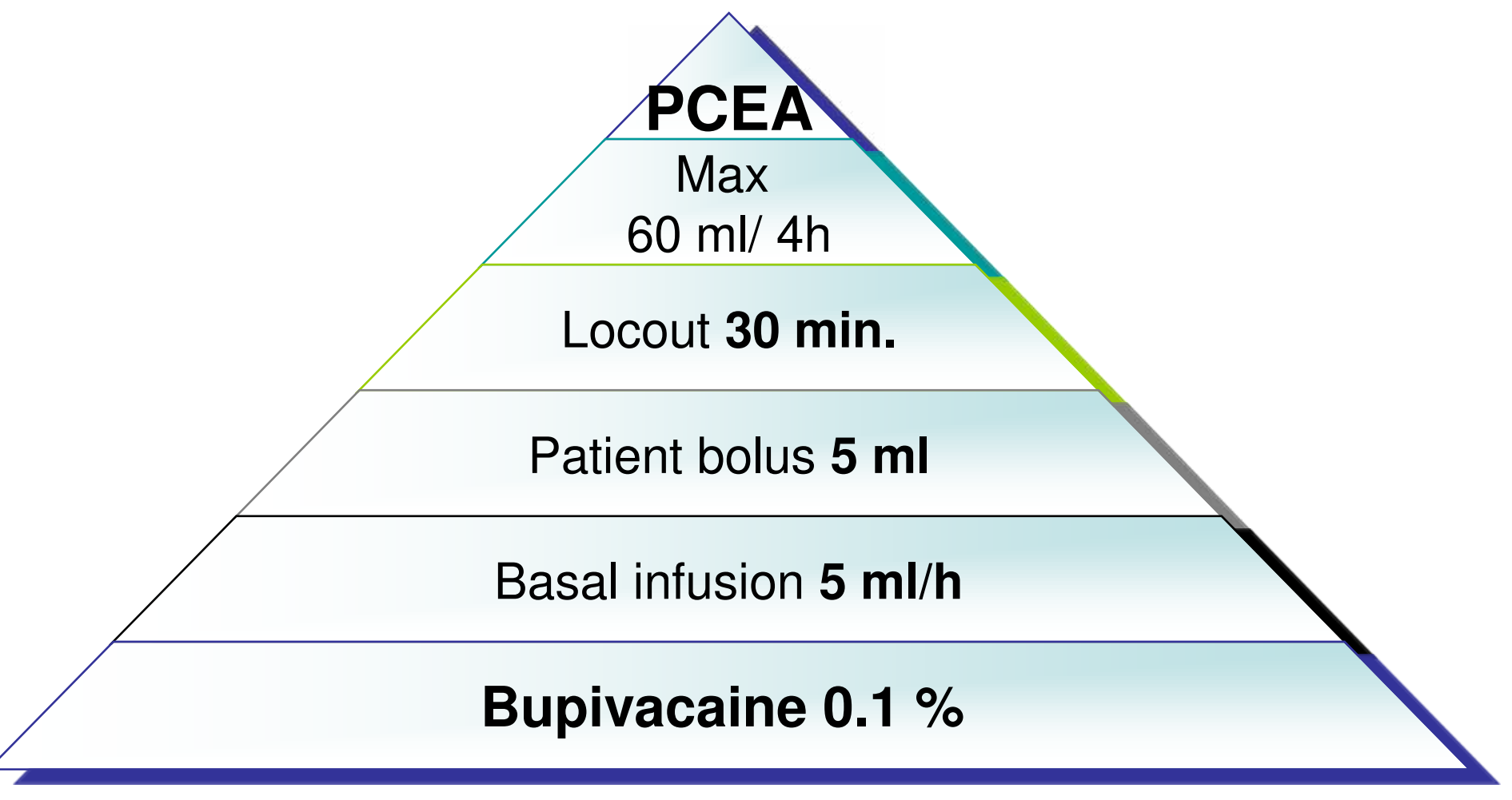

4. Mobilisation trial was performed at $6 \mathrm{PM}$ on the surgery's day. Patients had to stand without assistance for 60 seconds. Trial failure was defined as bradicardia ( $\mathrm{HR}<50 \mathrm{~b} / \mathrm{min})$ and/or arterial hypotension (MAP<55 mmHg).

5. Consumption of bupivacaine, maximum pain intensity during postoperative $24 \mathrm{~h}$ with numeric rating score (NRS), patient's overall satisfaction level by score of [0-10] assessed, and mobilisation trial failure/success were recorded.

\section{Conclusions:}

Postoperative epidural analgesia does not limit early patient mobilisation. The use of CSEA as part of ERAS pathways is feasible in THA surgery patients.

Protocol was part of bigger RCT: Markevicius et al. Electronics and Electrical Engineering, 2016. DOI: http://dx.doi.org/10.5755/j01.eee.22.1.12826

\section{Study design}

Blood sample, thromboelastometry, perfusion

Continuous blood pressure, tissue's oxygenation non-invasive hemoglobin

Spinal anesthesia $\left(L_{2-3}\right)+$ epidural catheterization

Mini voloume loading test $(\mathrm{mVLT})-2.5 \mathrm{ml} / \mathrm{kg} / 5 \mathrm{~min}$

Total hip arthroplasty

PACU, start PCEA (at Bromage scale 2)

mVLT, mobilization test - evening 6 PM

General ward, stop PCEA - morning 8 AM

Results:

\begin{tabular}{|c|c|}
\hline $\begin{array}{l}\text { Pain (NRS) first } 24 \mathrm{~h} \\
\text { (with PCEA regimen) }\end{array}$ & $4(3 ; 6)$ \\
\hline $\begin{array}{l}\text { Bupivacaine overall } \\
\text { consumption }\end{array}$ & $142.45 \pm 34.22 \mathrm{mg}$ \\
\hline $\begin{array}{l}\text { Bupivacaine dose } \\
\text { mean/1h }\end{array}$ & $7.09 \pm 1.66 \mathrm{mg}$ \\
\hline $\begin{array}{l}\text { Demanded/administered } \\
\text { boluses (D/A) }\end{array}$ & $66,67 \%(40.78 ; 84.52)$ \\
\hline $\begin{array}{l}\text { Paracetamol 1g (pain } \\
\text { rescue) }\end{array}$ & 2 subjects $(2.53 \%)$ \\
\hline $\begin{array}{l}\text { Early mobilization test } \\
\text { failed (brady < } 50 \mathrm{~b} / \mathrm{min} \text {.) }\end{array}$ & 9 subjects \\
\hline Minor motor block & 4 subjects \\
\hline $\begin{array}{l}\text { Epidural catheter } \\
\text { migration }\end{array}$ & 1 subject \\
\hline $\begin{array}{l}\text { Discharge criteria at } 48 \mathrm{~h} \\
(\mathrm{NRS} \leq 3)\end{array}$ & All - 79 patients \\
\hline Patient satisfaction & $9(9 ; 10)$ \\
\hline
\end{tabular}

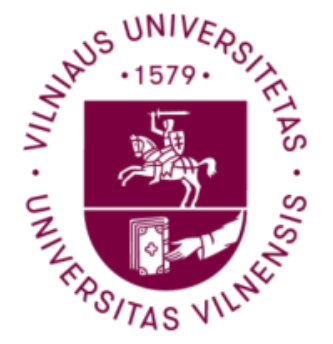

